\title{
"Green propellants" as a hydrazine substitute: experimental investigations of ethane/ethene-nitrous oxide mixtures and validation of detailed reaction mechanism
}

\author{
Corina Janzer $^{1} \mathbb{D} \cdot$ Sandra Richter $^{1} \mathbb{D} \cdot$ Clemens Naumann $^{1}(\mathbb{D}) \cdot$ Torsten Methling $^{1}(\mathbb{D}$
}

Received: 29 January 2021 / Revised: 13 April 2021 / Accepted: 8 May 2021 / Published online: 28 May 2021

(c) The Author(s) 2021

\begin{abstract}
Mixtures of hydrocarbons and nitrous oxide are known as green propellants and could replace the highly toxic hydrazine and hydrazine derivatives as rocket fuel, since they are non-toxic and easier to handle, but still have a high specific impulse. Possible hydrocarbon candidates are ethane or ethene. To check the applicability of the two reaction systems, $\mathrm{C}_{2} \mathrm{H}_{6} / \mathrm{N}_{2} \mathrm{O}$ and $\mathrm{C}_{2} \mathrm{H}_{4} / \mathrm{N}_{2} \mathrm{O}$, experiments are a prerequisite for accurate predictions under various conditions that are of great importance for the design of safe and reliable thrusters. Therefore, experimental literature data obtained from ignition delay times and laminar burning velocities were used to validate and optimize a new reaction mechanism, which is designed for $\mathrm{C}_{0}-\mathrm{C}_{3}$ and nitrogen oxides formation. To achieve a better predictive power of the detailed mechanism, the Arrhenius parameters of three reactions were adjusted: $\mathrm{N}_{2} \mathrm{O}+\mathrm{H} \rightleftharpoons \mathrm{N}_{2}+\mathrm{OH}, \mathrm{N}_{2} \mathrm{O}(+\mathrm{M}) \rightleftharpoons \mathrm{N}_{2}+\mathrm{O}(+\mathrm{M})$, and $\mathrm{NH}+\mathrm{NO} \rightleftharpoons \mathrm{N}_{2} \mathrm{O}+\mathrm{H}$. A good agreement was achieved between simulation and experiment for ignition delay times at various pressures and equivalence ratios in a broad temperature range before and after the mechanism optimization. However, the laminar burning velocities in the whole measured range of the equivalence ratio for all pressures and dilutions showed a significant improvement after the optimization.
\end{abstract}

Keywords Chemical kinetics $\cdot$ Mechanism optimization $\cdot$ Laminar burning velocity $\cdot$ Ignition delay time $\cdot$ Nitrous oxide . Green propellants

\section{Introduction}

With its long-term stability and high specific impulse, hydrazine is an ideal storable rocket fuel for occasionally required propulsion applications, like attitude control systems for satellites. Hydrazine derivatives like monomethyl hydrazine $(\mathrm{MMH})$ and unsymmetrical dimethyl hydrazine (UDMH) are used for rocket propulsion applications in various technological contexts. All of these fuels have the same disadvantages in handling: they are highly toxic and carcinogenic [1]. In 2011, hydrazine was included in the list of "substances of very high concern" by the framework

Corina Janzer

Corina.Janzer@dlr.de

1 German Aerospace Center (DLR), Institute of Combustion Technology, Pfaffenwaldring 38-40, 70569 Stuttgart, Germany legislation of the European Commission for the Registration, Evaluation, Authorization and Restriction of Chemicals (REACH) [2]. Due to possible restrictions, the use of hydrazine will become expensive and impractical on short to medium notice. At given moment, several tons of hydrazine are still consumed annually in European space activities. The DLR Future Fuels initiative is investigating so-called green propellants as hydrazine alternatives [3, 4]. High potential candidates are hydrocarbon-nitrous oxide mixtures, since they are less or non-toxic, have a high specific impulse, and are less expensive. However, higher flame temperatures and the increased risk of flashbacks in premixed propulsion systems lead to specific design requirements for new satellite in-space propulsion thrusters [5, 6]. Numerical CFD approaches are commonly used to find the ideal geometry. For this, a precise knowledge of combustion chemistry is required.

Mixtures of hydrocarbons and nitrous oxide get into the focus of science in the latest years. Besides the DLR, research programs in the US initiated by the Defense Advanced Research Projects Agency (DARPA) [7] are 
investigating such mixtures, especially $\mathrm{C}_{2} \mathrm{H}_{2} / \mathrm{N}_{2} \mathrm{O}$ [8] and $\mathrm{C}_{3} \mathrm{H}_{8} / \mathrm{N}_{2} \mathrm{O}$ [9]. In 2009, Mungas et al. [10, 11] started testing mixtures in thrusters with ethane, ethene, or ethyne with nitrous oxides. Various studies on the detailed chemical kinetics have been conducted in the past. Powell et al. used laminar burning velocities for optimizing the chemical kinetic mechanism [12], as well as flame structure measurements, flow reactor data, and shock tube ignition delay data [13]. Mathieu et al. [14] developed a detailed $\mathrm{C}_{1} / \mathrm{NO}_{X}$ model which predicts the influence of $\mathrm{N}_{2} \mathrm{O}$ on the ignition of methane. In 2019, Wang and Zhang [15] published a mechanism for predicting laminar burning velocities of hydrocarbon/ $\mathrm{N}_{2} \mathrm{O}$ flames, especially for $\mathrm{C}_{2} \mathrm{H}_{4}$, but also tested for experimental data from Powell et al. [12] $\left(\mathrm{CH}_{4}, \mathrm{C}_{2} \mathrm{H}_{2}, \mathrm{C}_{3} \mathrm{H}_{8}\right)$ and Naumann et al. [16] $\left(\mathrm{C}_{2} \mathrm{H}_{4}\right)$.

This contribution reports on the validation and optimization of a detailed reaction mechanism for ethane- or ethenenitrous oxide reaction systems $\left(\mathrm{C}_{2} \mathrm{H}_{6} / \mathrm{N}_{2} \mathrm{O}\right.$ or $\left.\mathrm{C}_{2} \mathrm{H}_{4} / \mathrm{N}_{2} \mathrm{O}\right)$. Experimental data from literature of two global combustion parameters, laminar burning velocity and ignition delay time, were used for the validation and optimization [17-20]. Furthermore, sensitivity analyses and the resulting implications to reaction kinetics of nitrogen-containing species are investigated to evaluate the predictive potential of the mechanism. In future work, this detailed optimized mechanism serves as the basis for a reduced mechanism, which should be used in CFD simulations.

\section{Experimental data}

All experiments shown here were carried out at the DLR Institute of Combustion Technology in Stuttgart, Germany. Ignition delay times have been measured behind reflected shock waves at the shock tube facility for both reaction systems, $\mathrm{C}_{2} \mathrm{H}_{4} / \mathrm{N}_{2} \mathrm{O}$ and $\mathrm{C}_{2} \mathrm{H}_{6} / \mathrm{N}_{2} \mathrm{O}$. The results and details about the experiments and the construction of the devices were published in 2017 [17], 2019 [18], and 2020 [19]. The shock tube used is divided by aluminum diaphragms into the high-pressure driver section and the low-pressure driven section. The driven section was filled with small quantities of the homogenized mixtures at equivalence ratios $\varphi=1.0$ and 2.0, diluted 1:5 with nitrogen; the driver section was loaded with mixtures of helium and argon. After diaphragm rupture, a shock wave propagates through the reaction mixture and eventually becomes reflected at the end plate. The temperature and pressure directly behind the reflected shock wave were computed from the incident shock velocity measured by piezoelectric pressure gages. The temperature range examined was approximately $1100-2000 \mathrm{~K}$, at initial pressures of $p=1,4$, and $16 \mathrm{bar}$, respectively. Ignition was observed by the detection of photon emission from excited $\mathrm{CH}(\mathrm{A})$ at $431 \mathrm{~nm}$ with photomultipliers. Ignition delay time values shown in this paper were determined by the occurrence of the first $\mathrm{CH}(\mathrm{A})$ maximum after the initiation of the reactive system by the reflected shock wave.

Laminar burning velocities have been measured with a high-pressure burner system using the cone angle method. The experimental setup consists of the burner housing with the pressure control system, the exhaust gas heat exchanger, the ignition system, and the flame holder. For all experiments, the flame holder is heated up to $473 \mathrm{~K}$ and the dilution with nitrogen was $50 \%$. The reaction system $\mathrm{C}_{2} \mathrm{H}_{4} / \mathrm{N}_{2} \mathrm{O}$ has been measured between equivalence ratios $\varphi=0.6$ and 1.8 at pressures $p=1$ and 3 bar by Kick et al. [17] and at $p=6$ bar by Richter et al. [20]. The reaction system $\mathrm{C}_{2} \mathrm{H}_{6} /$ $\mathrm{N}_{2} \mathrm{O}$ was examined under the same conditions as $\mathrm{C}_{2} \mathrm{H}_{4} / \mathrm{N}_{2} \mathrm{O}$ [20]. Also, the influence of heat transfer to the flame holder was tested at $p=1$ bar varying the dilution ( $40 \%$ and $60 \%)$. For the evaluation, digital images of the conical flames were captured by a CCD camera in combination with a telecentric zoom lens to determine the cone angle of the flame $(\alpha)$. Based on the cone angle and the gas velocity $\left(v_{\mathrm{u}}\right)$ known from the experiment, the laminar burning velocity $\left(S_{\mathrm{u}}\right)$ is calculated by the equation $S_{\mathrm{u}}=v_{\mathrm{u}} \bullet \sin (\alpha)$.

\section{Chemical kinetic mechanism}

The chemical kinetic mechanism used for the simulation of the experiments is based on the in-house developed model DLR SynNG for the combustion of fuel mixtures of syngas and natural gas [21]. This $\mathrm{C}_{0}-\mathrm{C}_{3}$ model has already been optimized with experimental data including ignition delay times, species profiles, and laminar burning velocities. Since nitrous oxide was also present as a reactant in the experiments considered here, the mechanism was expanded with a sub-mechanism for the combustion of nitrogen oxides. In doing so, the reactions with nitrogen-containing species from the Glarborg et al. model from 2018 [22] were subjoined. The entire mechanism includes 165 species and 1410 reactions and is denoted by DLR SynNG $+\mathrm{NO}$ v0.0. All chemical kinetic simulations were performed with the open source software Cantera [23].

\section{Mechanism optimization}

The modified and optimized versions of the model were generated with help of the linear transformation model (linTM) [24]. The linTM very efficiently analyses the relations between reaction rates of chemical kinetic mechanisms and experimental data. Thus, the global sensitivity analysis of the linTM was applied to identify the reactions with the highest impact on the simulation results at the investigated experimental conditions. The reaction sensitivities from the 
linTM are combining the three Arrhenius coefficients or rates $k(T)$ at three temperatures (k3 method of the linTM), respectively. Therefore, the sensitivities of each rate $k(T)$ span a vector in a three-dimensional space. The length of this vector is defined as the reaction sensitivity of the linTM, and is therefore positive:
$\mathrm{N}_{2} \mathrm{O}+\mathrm{H} \rightleftharpoons \mathrm{N}_{2}+\mathrm{OH}$

Also important for burning velocity prediction is reaction R3:

$\mathrm{NH}+\mathrm{NO} \rightleftharpoons \mathrm{N}_{2} \mathrm{O}+\mathrm{H}$

$S_{r}=\sqrt{\left(\frac{\partial \ln Q}{\partial \ln k\left(T_{1}\right)} \Delta \ln k\left(T_{1}\right)_{\max }\right)^{2}+\left(\frac{\partial \ln Q}{\partial \ln k\left(T_{2}\right)} \Delta \ln k\left(T_{2}\right)_{\max }\right)^{2}+\left(\frac{\partial \ln Q}{\partial \ln k\left(T_{3}\right)} \Delta \ln k\left(T_{3}\right)_{\max }\right)^{2}}$

for which $Q$ is the quantity of interest (e.g. ignition delay time or laminar flame speed). The sensitivities of each rate are normalized with their $2 \sigma$ uncertainty $\Delta \ln k(T)_{\max }$.

Figures 1 and 2 show rate sensitivity coefficients for exemplarily selected simulation conditions for both reaction systems and both types of investigated experiments with the aforementioned mechanism DLR SynNG + NO v0.0. The results for the remaining experimental conditions are comparable.

It can be seen that for both burning velocity and ignition delay time, the two reactions R1 and R2 have major impact on the predictive power of the model:

$\mathrm{N}_{2} \mathrm{O}(+\mathrm{M}) \rightleftharpoons \mathrm{N}_{2}+\mathrm{O}(+\mathrm{M})$

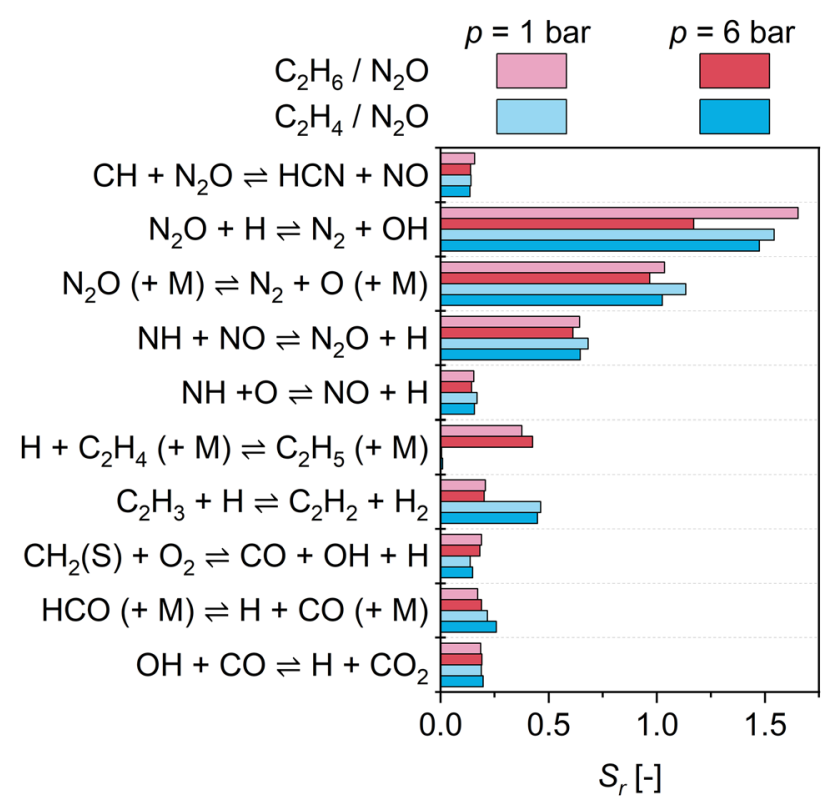

Fig. 1 Global sensitivity coefficients (Eq. 1) of the 10 most sensitive reactions for the measured laminar burning velocity maximum at $T=473 \mathrm{~K}$, and $p=1$ bar (bright) or $p=6$ bar (dark), each for $\mathrm{C}_{2} \mathrm{H}_{6}$ / $\mathrm{N}_{2} \mathrm{O}$ (red) and $\mathrm{C}_{2} \mathrm{H}_{4} / \mathrm{N}_{2} \mathrm{O}$ (blue) mixtures. Sensitivity coefficients normalized to uncertainty of rate constant of the respective reaction
These observations are consistent with the results of Powell et al. [12] from 2009. Powell et al. only optimized reaction R2 and described the reaction rate as the sum of two Arrhenius expressions. Reaction rate of R1 left untouched by Powell et al. based on consistent literature data; Reaction R3 was not changed by Powell et al., since it only plays a minor role.

In the first optimization step within this work, only the Arrhenius parameters of reaction R2 from Klippenstein et al. [25] of the Glarborg et al. model [22] were replaced in the DLR SynNG + NO v0.0 mechanism by the values from Powell et al. [12], to create the model DLR SynNG + NO v0.1.

In a second step, a parameter optimization was performed with the k3 method of linTM [24] and the model DLR SynNG + NO v0.2 was created. Therefore, the Arrhenius parameters of the selected reactions $\mathrm{R} 1, \mathrm{R} 2$, and $\mathrm{R} 3$ are changed under the boundary condition that at three

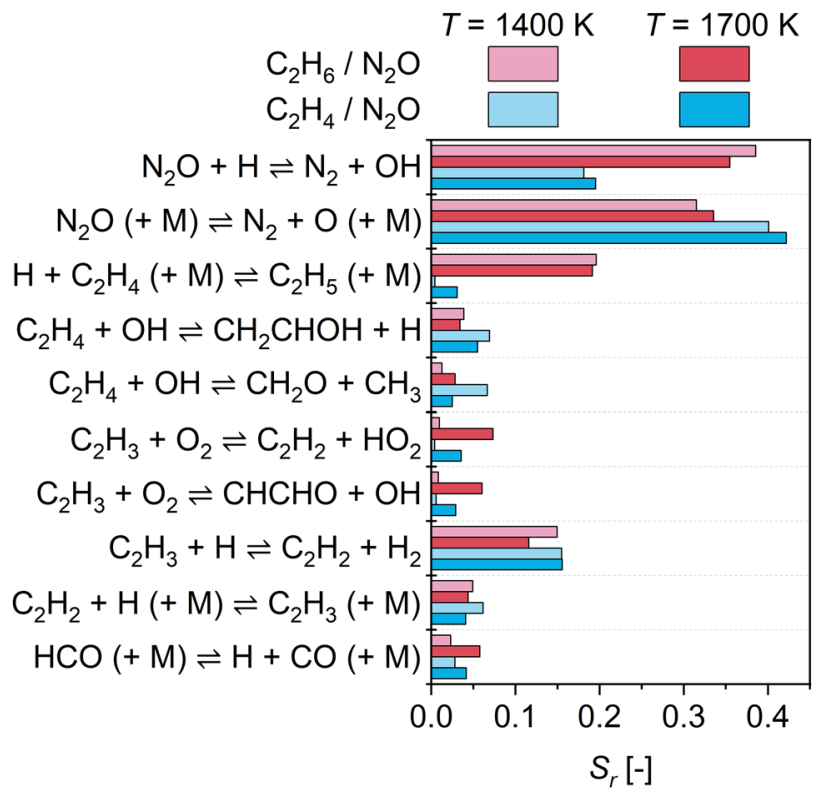

Fig. 2 Global sensitivity coefficients (Eq. 1) of the 10 most sensitive reactions for the ignition delay time at $T=1400 \mathrm{~K}$ (bright) or $T=1700 \mathrm{~K}$ (dark), and $p=1 \mathrm{bar}$, each for stoichiometric $\mathrm{C}_{2} \mathrm{H}_{6} / \mathrm{N}_{2} \mathrm{O}$ (red) and $\mathrm{C}_{2} \mathrm{H}_{4} / \mathrm{N}_{2} \mathrm{O}$ (blue) mixtures. Sensitivity coefficients normalized to uncertainty of rate constant of the respective reaction 
Table 1 Used uncertainty values for optimization process in linTM at three selected temperatures (k3 method) [24]. Values in brackets corresponds to the $2 \sigma$ uncertainty

\begin{tabular}{|c|c|c|c|c|c|c|c|}
\hline \multirow[t]{2}{*}{ Reactions } & \multicolumn{3}{|c|}{ Temperatures (K) } & \multicolumn{3}{|c|}{ Uncertainties (-) } & \multirow[t]{2}{*}{ References } \\
\hline & $T_{1}$ & $T_{2}$ & $T_{3}$ & $d \log k\left(T_{1}\right)$ & $d \log k\left(T_{2}\right)$ & $d \log k\left(T_{3}\right)$ & \\
\hline $\mathrm{N}_{2} \mathrm{O}(+\mathrm{M}) \rightleftharpoons \mathrm{N}_{2}+\mathrm{O}(+\mathrm{M})\left(k_{\infty}\right)$ & 1000 & 1648 & 3000 & $0.172(0.5)$ & $-0.027(0.5)$ & $-0.445(0.5)$ & [26] \\
\hline $\mathrm{N}_{2} \mathrm{O}(+\mathrm{M}) \rightleftharpoons \mathrm{N}_{2}+\mathrm{O}(+\mathrm{M})\left(k_{0}\right)$ & 1000 & 1648 & 3000 & $0.230(0.3)$ & $0.128(0.3)$ & $-0.134(0.3)$ & [26] \\
\hline $\mathrm{N}_{2} \mathrm{O}+\mathrm{H} \rightleftharpoons \mathrm{N}_{2}+\mathrm{OH}$ & 298 & 667 & 2000 & $\begin{array}{l}-0.708(0.5) \\
-0.619(0.5)\end{array}$ & $\begin{array}{l}0.671(0.5) \\
-0.747(0.5)\end{array}$ & $\begin{array}{l}-0.176(0.5) \\
0.097(0.5)\end{array}$ & est \\
\hline $\mathrm{NH}+\mathrm{NO} \rightleftharpoons \mathrm{N}_{2} \mathrm{O}+\mathrm{H}$ & 298 & 1200 & 2000 & $-0.213(0.3)$ & $0.113(0.3)$ & $-0.676(0.5)$ & {$[26]$} \\
\hline
\end{tabular}

Table. 2 Overview of original and modified Arrhenius parameters of adapted reactions $\mathrm{R} 1, \mathrm{R} 2$, and R3

\begin{tabular}{|c|c|c|c|c|}
\hline Reaction & $A$ & $n$ & $E_{\mathrm{a}}$ & References \\
\hline \multicolumn{5}{|c|}{$\mathrm{N}_{2} \mathrm{O}(+\mathrm{M}) \rightleftharpoons \mathrm{N}_{2}+\mathrm{O}(+\mathrm{M})\left(k_{\infty}\right)$} \\
\hline DLR SynNG + NO v0.0 & $9.90 \mathrm{E}+10$ & 0.00 & $5.790 \mathrm{E}+04$ & {$[22]$} \\
\hline DLR SynNG + NO v0.1 & $9.90 \mathrm{E}+10$ & 0.00 & $5.790 \mathrm{E}+04$ & {$[22]$} \\
\hline DLR SynNG + NO v0.2 & $1.42 \mathrm{E}+24$ & -3.86 & $6.055 \mathrm{E}+04$ & See text \\
\hline \multicolumn{5}{|c|}{$\mathrm{N}_{2} \mathrm{O}(+\mathrm{M}) \rightleftharpoons \mathrm{N}_{2}+\mathrm{O}(+\mathrm{M})\left(k_{0}\right)$} \\
\hline DLR SynNG + NO v0.0 & $6.00 \mathrm{E}+14$ & 0.00 & $5.744 \mathrm{E}+04$ & {$[22]$} \\
\hline DLR SynNG + NO v0.1 & $6.00 \mathrm{E}+14$ & 0.00 & $5.744 \mathrm{E}+04$ & {$[22]$} \\
\hline DLR SynNG + NO v0.2 & $5.83 \mathrm{E}+30$ & -4.26 & $7.068 \mathrm{E}+04$ & see text \\
\hline \multicolumn{5}{|l|}{$\mathrm{N}_{2} \mathrm{O}+\mathrm{H} \rightleftharpoons \mathrm{N}_{2}+\mathrm{OH}$} \\
\hline DLR SynNG + NO v0.0 & $6.40 \mathrm{E}+07$ & 1.84 & $1.349 \mathrm{E}+04$ & {$[22,25]$} \\
\hline DLR SynNG + NO v0.1 & $\begin{array}{l}2.93 \mathrm{E}+10 \\
5.82 \mathrm{E}+14\end{array}$ & $\begin{array}{l}0.00 \\
0.00\end{array}$ & $\begin{array}{l}4.750 \mathrm{E}+03 \\
1.788 \mathrm{E}+04\end{array}$ & {$[12]$} \\
\hline DLR SynNG + NO v0.2 & $\begin{array}{l}8.79 \mathrm{E}+43 \\
9.06 \mathrm{E}-07\end{array}$ & $\begin{array}{l}-9.81 \\
5.81\end{array}$ & $\begin{array}{l}1.845 \mathrm{E}+04 \\
8.977 \mathrm{E}+03\end{array}$ & See text \\
\hline \multicolumn{5}{|l|}{$\mathrm{NH}+\mathrm{NO} \rightleftharpoons \mathrm{N}_{2} \mathrm{O}+\mathrm{H}$} \\
\hline DLR SynNG + NO v0.0 & $2.70 \mathrm{E}+15$ & -0.78 & $2.000 \mathrm{E}+01$ & {$[22]$} \\
\hline DLR SynNG + NO v0.1 & $2.70 \mathrm{E}+15$ & -0.78 & $2.000 \mathrm{E}+01$ & {$[22]$} \\
\hline DLR SynNG + NO v0.2 & $5.78 \mathrm{E}+58$ & -13.80 & $1.605 \mathrm{E}+04$ & See text \\
\hline
\end{tabular}

Specific reaction rate constants have form $k=A \cdot T^{n} \cdot \exp \left(-E_{\mathrm{a}} / \mathrm{RT}\right)$

Units: $A$ : in combinations of $\mathrm{cm}, \mathrm{mol}, \mathrm{s} ; E_{\mathrm{a}}$ in $\mathrm{cal} / \mathrm{mol}$ selected temperatures the resulting rate constant lies within a previously defined uncertainty range of $3 \sigma$ (see Tab. 1). The Arrhenius parameters of all modified reactions from the three different models are shown in Tab. 2. The values are fitted parameters for a better agreement between experiment and simulation. To make the changes more visible and to be able to better compare the original with the modified reaction rate constants, the temperature dependence of the reaction rates is shown in Fig. 3.

All other most sensitive reactions usually do not contain any $N$-containing species (see Figs. 1 and 2). These have not been changed because the $\mathrm{C}_{0}-\mathrm{C}_{3}$ model has already been optimized [21].

\section{Results and discussion}

\subsection{Ignition delay time}

Experimental ignition delay time results as a function of the inverse temperature are shown in Figs. 4, 5, 6, 7 for both reaction systems, $\mathrm{C}_{2} \mathrm{H}_{4} / \mathrm{N}_{2} \mathrm{O}$ and $\mathrm{C}_{2} \mathrm{H}_{6} / \mathrm{N}_{2} \mathrm{O}$, for stoichiometric $(\varphi=1.0)$ and fuel-rich $(\varphi=2.0)$ conditions respectively. At the $\mathrm{C}_{2} \mathrm{H}_{4} / \mathrm{N}_{2} \mathrm{O}$ reaction system (Figs. 4 and 5), the original mechanism already showed a satisfactory match for ignition delay times. Nevertheless, an improvement could be achieved by the adaptation of the model (DLR SynNG + NO v0.1). The optimized model (DLR SynNG + NO v0.2) shows an outstanding agreement with the experimental data over the entire temperature range at all pressures, both at $\varphi=1$ and $\varphi=2$. 


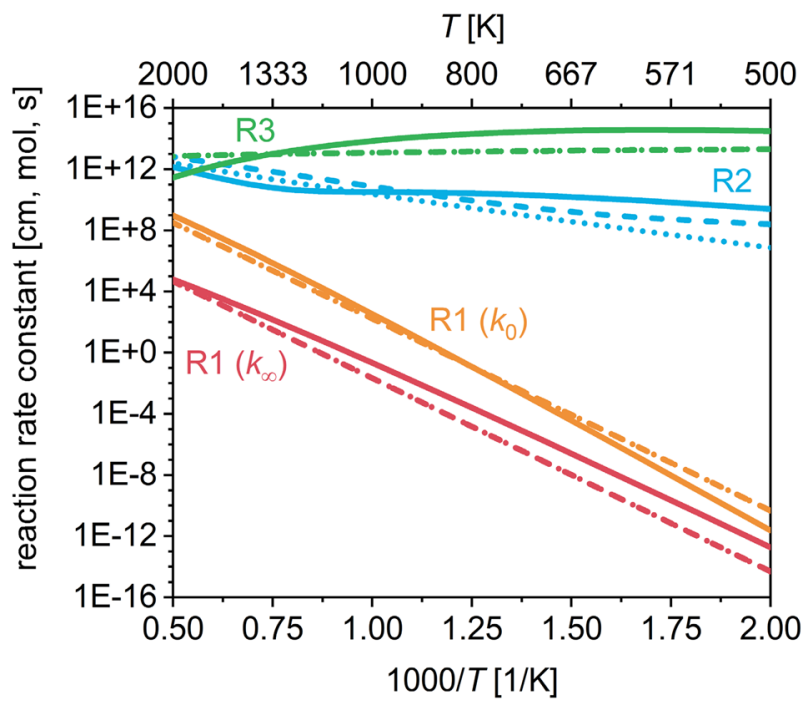

Fig. 3 Comparison of original and modified reaction rates for $\mathrm{R} 1 \quad\left(\mathrm{~N}_{2} \mathrm{O} \quad(+\mathrm{M}) \rightleftharpoons \mathrm{N}_{2}+\mathrm{O} \quad(+\mathrm{M})\right.$; red and orange), R2 $\left(\mathrm{N}_{2} \mathrm{O}+\mathrm{H} \rightleftharpoons \mathrm{N}_{2}+\mathrm{OH} ; \quad\right.$ blue $)$ and $\mathrm{R} 3 \quad\left(\mathrm{~N}_{2} \mathrm{O}+\mathrm{H} \rightleftharpoons \mathrm{N}_{2}+\mathrm{OH}\right.$; green). Dotted lines: DLR SynNG $+\mathrm{NO} v 0.0$; dashed lines: DLR SynNG + NO v0.1; solid lines: DLR SynNG + NO v0.2

Figures 6 and 7 show the results for the reaction system $\mathrm{C}_{2} \mathrm{H}_{6} / \mathrm{N}_{2} \mathrm{O}$. It can be seen here that the simulation results of mechanisms DLR SynNG + NO v0.0 and DLR SynNG + NO v0.2 hardly differ and both provide very good agreement with experimental data. The strong increase of the ignition delay time at atmospheric pressure for temperatures below about $1450 \mathrm{~K}$ for the stoichiometric and about $1600 \mathrm{~K}$ for the fuel-rich mixture indicates an apparent increase in the global activation energy [18]. This is not reproduced by any of the models used.

The mechanism, in which only the rate constant of R2 was changed (DLR SynNG + NO v0.1), predicts ignition delay times that are too fast compared to the experimental results, especially for low temperatures. This can be explained with help of the sensitivity analysis in Fig. 2. There it can be seen that in the $\mathrm{C}_{2} \mathrm{H}_{6} / \mathrm{N}_{2} \mathrm{O}$ system the reactions $\mathrm{N}_{2} \mathrm{O}+\mathrm{H} \rightleftharpoons \mathrm{N}_{2}+\mathrm{OH}(\mathrm{R} 2)$ and $\mathrm{N}_{2} \mathrm{O}(+\mathrm{M}) \rightleftharpoons \mathrm{N}_{2}+\mathrm{O}$ $(+\mathrm{M})(\mathrm{R} 1)$ are both highly sensitive, whereas in the $\mathrm{C}_{2} \mathrm{H}_{4} /$ $\mathrm{N}_{2} \mathrm{O}$ system the sensitivity is mostly dominated by $\mathrm{R} 1$. When the Arrhenius parameters are only changed for R2, the effects on the ignition delay times of mixtures with $\mathrm{C}_{2} \mathrm{H}_{4}$ are significantly smaller. Therefore, there is no big change in Figs. 4 and 5 for model DLR SynNG + NO v0.1 compared to the original mechanism. However, if only reaction $\mathrm{R} 2$ is accelerated in reaction system $\mathrm{C}_{2} \mathrm{H}_{6} / \mathrm{N}_{2} \mathrm{O}$ (see Fig. 3), the branching ratio between $\mathrm{R} 1$ and $\mathrm{R} 2$ is severely impaired. This consequently leads to a change in the formation of radicals at starting reactions of $\mathrm{N}_{2} \mathrm{O}$ and thus leading to faster ignition.

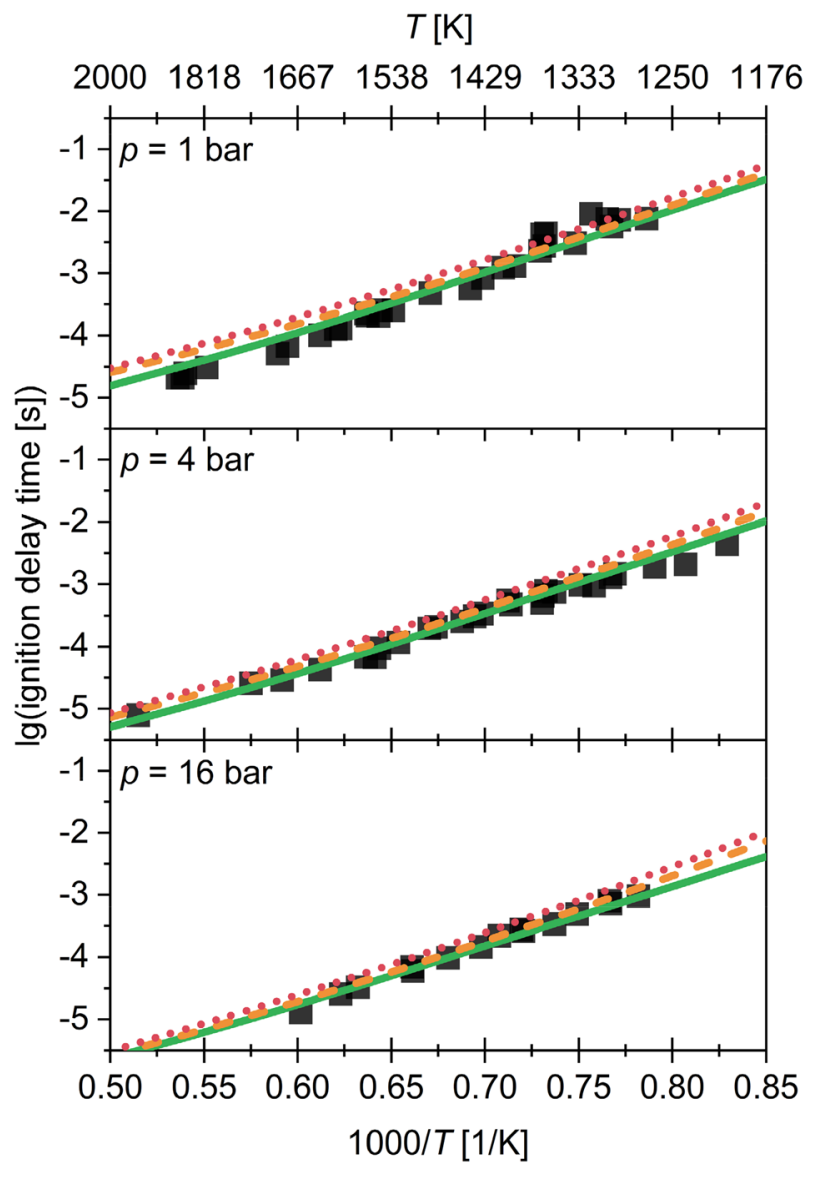

Fig. 4 Comparison between experimental and modeling ignition delay time results for $\mathrm{C}_{2} \mathrm{H}_{4} / \mathrm{N}_{2} \mathrm{O}(\varphi=1.0)$ at $p=1,4$, and 16 bar. Lines: Simulations (red dotted: DLR SynNG + NO v0.0; orange dashed: DLR SynNG + NO v0.1; green solid: DLR SynNG+NO v0.2). Squares: experimental data from Naumann et al. [18, 19]

\subsection{Laminar burning velocity}

Laminar burning velocities results for ethane/nitrous oxide and ethane/nitrous oxide are depicted in Figs. 8, 9, 10. Experimental (squares) and simulation results (lines) are shown as a function of equivalence ratio at an initial temperature of $473 \mathrm{~K}$ for different pressures ( $p=1,3$, and $6 \mathrm{bar}$ ) and dilution with nitrogen $d\left(\mathrm{~N}_{2}\right)=50 \%$; for reaction system $\mathrm{C}_{2} \mathrm{H}_{6} / \mathrm{N}_{2} \mathrm{O}$ also for different dilutions $\left(d\left(\mathrm{~N}_{2}\right)=40,50\right.$, and $60 \%)$ at $p=1$ bar.

Figure 8 depicts the effect of the changes in the Arrhenius parameters in the mechanism optimization affecting the prediction quality of the model, especially at $p=1$ bar. With the original model (DLR SynNG + NO v0.0, red dotted line), there are large differences of up to $0.22 \mathrm{~m} / \mathrm{s}$ between model and experiment. With every optimization step (from red dotted to orange dashed line, and from orange dashed to green solid line), the correspondence improves; even the changes in rate constants of $\mathrm{R} 2\left(\mathrm{~N}_{2} \mathrm{O}+\mathrm{H} \rightleftharpoons \mathrm{N}_{2}+\mathrm{OH}\right)$ in DLR 
$T[\mathrm{~K}]$

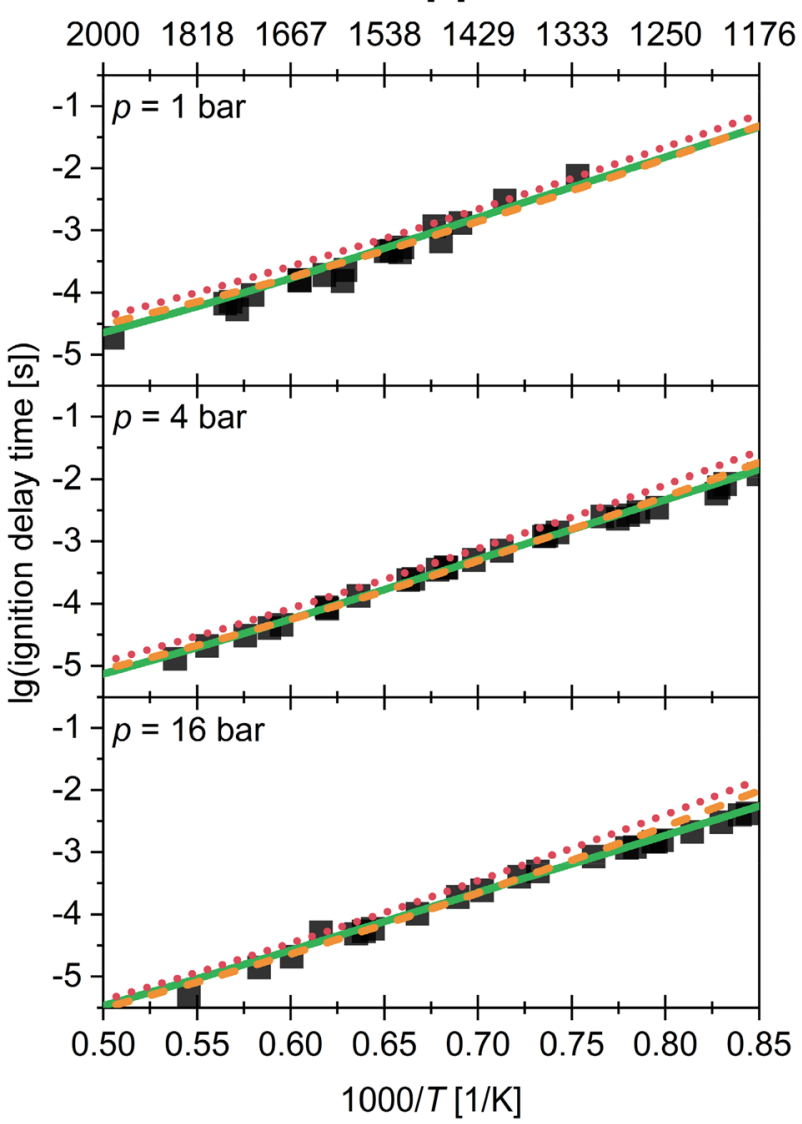

Fig. 5 Comparison between experimental and modeling ignition delay time results for $\mathrm{C}_{2} \mathrm{H}_{4} / \mathrm{N}_{2} \mathrm{O}(\varphi=2.0)$ at $p=1,4$, and 16 bar. Lines: Simulations (red dotted: DLR SynNG + NO v0.0; orange dashed: DLR SynNG + NO v0.1; green solid: DLR SynNG+NO v0.2). Squares: experimental data from Naumann et al. [18, 19]

SynNG + NO v0.1 (orange dashed line) have an immense influence. This is due to the change from the single-term Arrhenius rate expression from Klippenstein et al. [25] to the double-term Arrhenius rate expression from Powell et al. [12]. While the expression from Klippenstein stems from a theoretical work with focus on a good prediction of $\mathrm{NNH}$ and the products from the $\mathrm{N}_{2} \mathrm{O}+\mathrm{H}$ reaction in total, Powell et al. chose the double-term expression to refit experimental data from Marshall et al. [27], Hidaka et al. [28], and Dean et al. [29] from low to high temperature. This results finally in an improvement of the prediction of the experimental flame speed data from Powell et al.

The smallest differences between experiment and model are obtained at the maximum laminar burning velocity with the mechanism from the second optimization step (DLR SynNG + NO v0.2, green solid line), while the mechanism from the first optimization step (DLR SynNG + NO v0.1, orange dashed line) also delivers good results for fuel-rich mixtures at $p=1$ bar and especially at $p=6$ bar.
$T[\mathrm{~K}]$

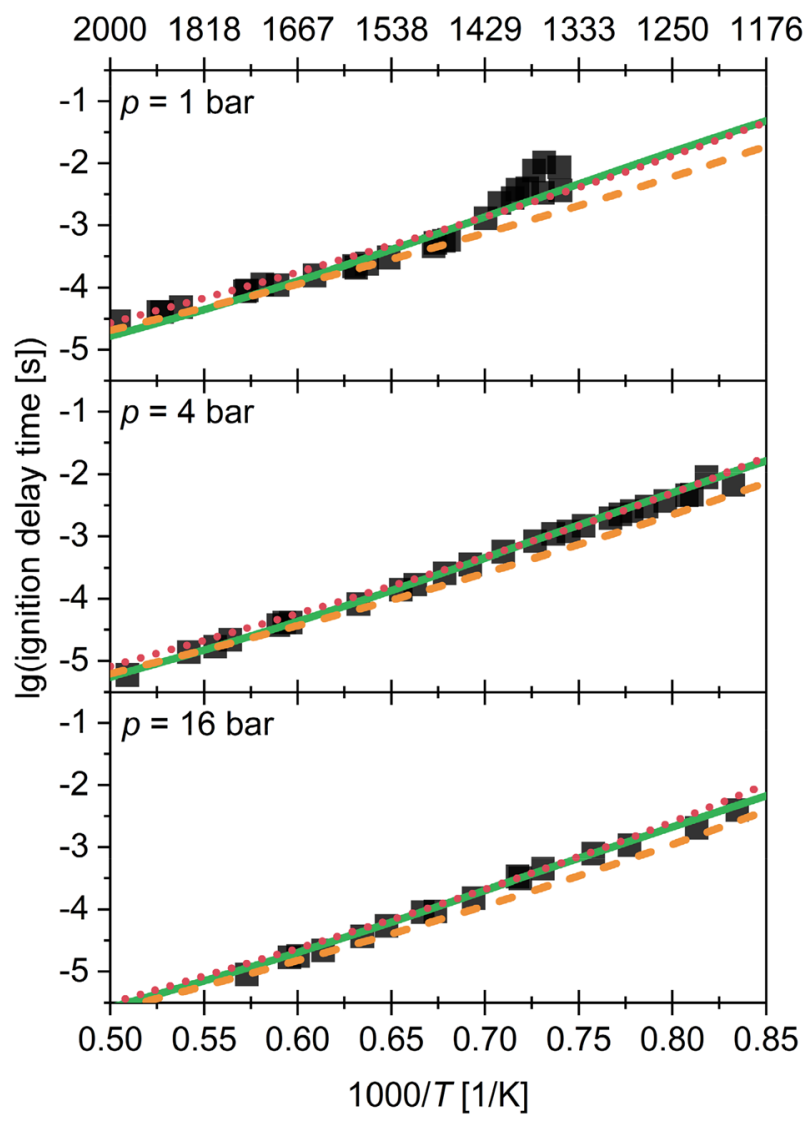

Fig. 6 Comparison between experimental and modeling ignition delay time results for $\mathrm{C}_{2} \mathrm{H}_{6} / \mathrm{N}_{2} \mathrm{O}(\varphi=1.0)$ at $p=1,4$, and 16 bar. Lines: Simulations (red dotted: DLR SynNG + NO v0.0; orange dashed: DLR SynNG + NO v0.1; green solid: DLR SynNG+NO v0.2). Squares: experimental data from Naumann et al. [18]

The same applies to the results of ethane/nitrous oxide mixtures, see Fig. 9. At pressures of $p=1$ and 6 bar, the model with the three optimized reactions (solid line) is even able to reproduce the measurement data over the entire range of the equivalence ratio exactly. A small difference can only be seen at $p=3$ bar, but the qualitative trend is correct (same in Fig. 8 for $\mathrm{C}_{2} \mathrm{H}_{4} / \mathrm{N}_{2} \mathrm{O}$ mixtures). All models predict an influence of the pressure on the laminar burning velocity.

Furthermore, the influence of the dilution with nitrogen on the laminar burning velocity was simulated (see Fig. 10). Here too, the DLR SynNG + NO v0.2 mechanism (green solid line) provides the best results and, in all cases examined experimentally, a very good agreement for all equivalence ratios. Therefore, this mechanism can also be used to predict laminar burning velocities without nitrogen dilution. 
$T[\mathrm{~K}]$

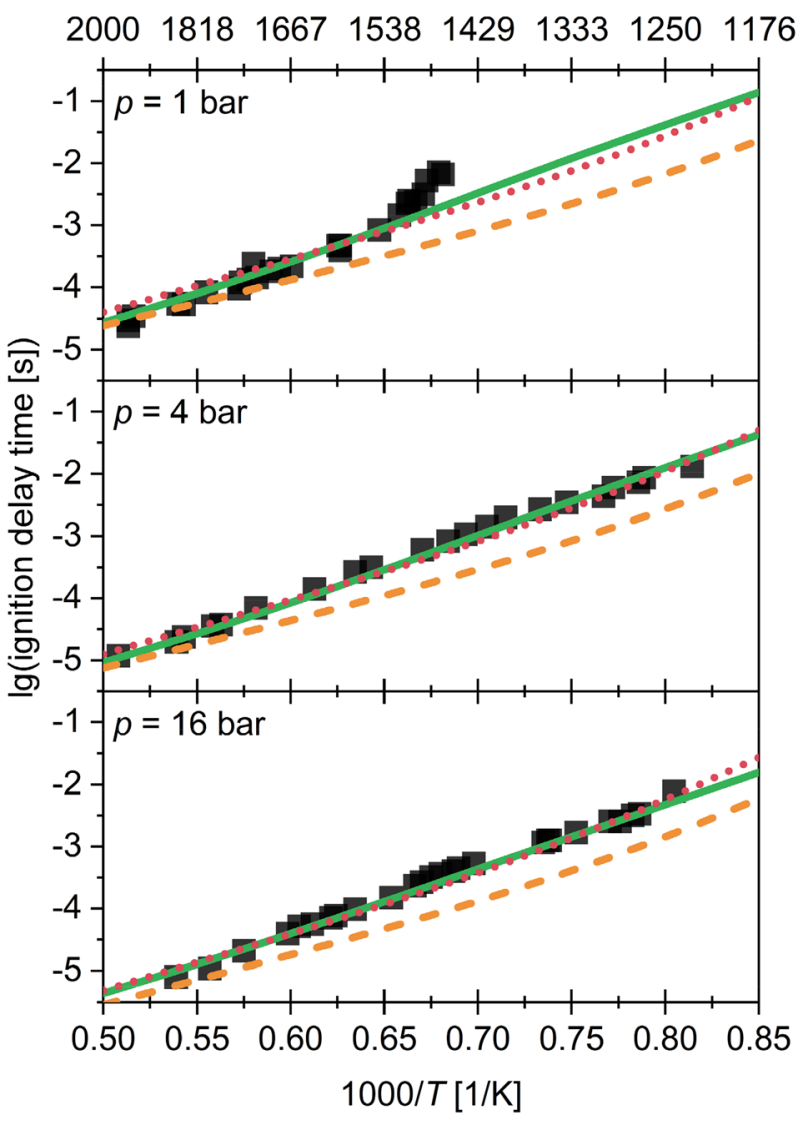

Fig. 7 Comparison between experimental and modeling ignition delay time results for $\mathrm{C}_{2} \mathrm{H}_{6} / \mathrm{N}_{2} \mathrm{O}(\varphi=1.0)$ at $p=1,4$, and 16 bar. Lines: Simulations (red dotted: DLR SynNG + NO v0.0; orange dashed: DLR SynNG + NO v0.1; green solid: DLR SynNG + NO v0.2). Squares: experimental data from Naumann et al. [18]

\section{Conclusion}

Ethane/nitrous oxide and ethene/nitrous oxide mixtures are possible candidates as green propellants, which could replace hydrazine and its derivatives as rocket fuel. Chemical kinetic mechanisms that predict the combustion behavior of these mixtures are necessary for the design of safe and reliable thrusters. As in this work, experimental literature data of global combustion parameters such as ignition delay times and laminar burning velocities are used to optimize detailed kinetic mechanisms. The starting point for the optimization was a mechanism for syngas and natural gas (DLR SynNG) by Methling et al. [21], coupled with the nitrogen oxide model by Glarborg et al. from 2018 [22]. With the help of sensitivity analyses, three reactions were identified that are of great importance for optimizing the mechanism:

$\mathrm{N}_{2} \mathrm{O}(+\mathrm{M}) \rightleftharpoons \mathrm{N}_{2}+\mathrm{O}(+\mathrm{M})$

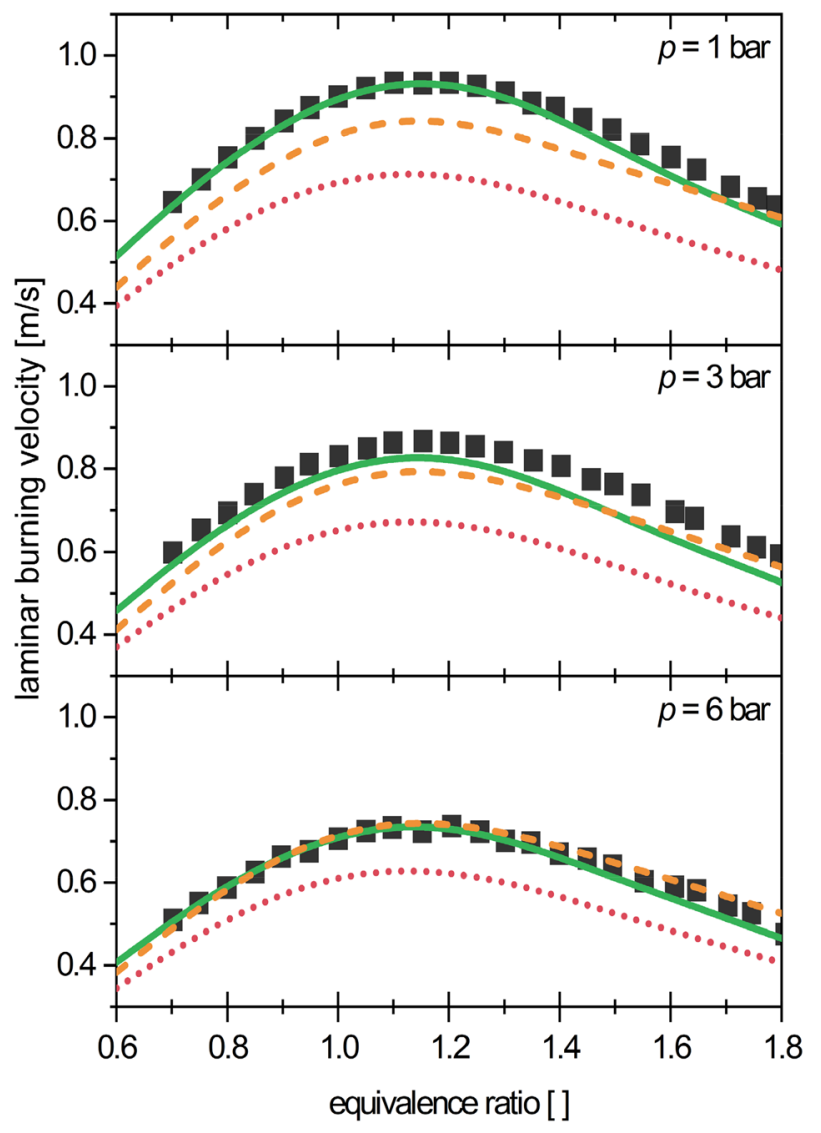

Fig. 8 Experimental laminar burning velocity results and model predictions for $\mathrm{C}_{2} \mathrm{H}_{4} / \mathrm{N}_{2} \mathrm{O}$ mixtures $\left(d\left(\mathrm{~N}_{2}\right)=50 \%, T=473 \mathrm{~K}\right)$ at $p=1$, 3 , and 6 bar. Lines: simulations (red dotted: DLR SynNG + NO v0.0; orange dashed: DLR SynNG $+\mathrm{NO}$ v0.1; green solid: DLR SynNG + NO v0.2. Squares: experimental data from Kick et al. [17] and Richter et al. [20]

$\mathrm{N}_{2} \mathrm{O}+\mathrm{H} \rightleftharpoons \mathrm{N}_{2}+\mathrm{OH}$

$\mathrm{NH}+\mathrm{NO} \rightleftharpoons \mathrm{N}_{2} \mathrm{O}+\mathrm{H}$.

The best agreement between model and experiment could be achieved for ignition delay times if the Arrhenius parameters were adjusted of all three reactions (mechanism DLR SynNG + NO v0.2). The same applies to the laminar burning velocities over entire range of equivalence ratio considered. With the changed Arrhenius parameters, the mechanism DLR SynNG + NO v0.2 is therefore able to predict laminar burning velocities and ignition delay times in the examined range correctly. In future work, this detailed optimized mechanism serves as the basis for a reduced mechanism, which should be used in CFD simulations.

Supplementary Information The online version contains supplementary material available at https://doi.org/10.1007/s12567-021-00370-8. 


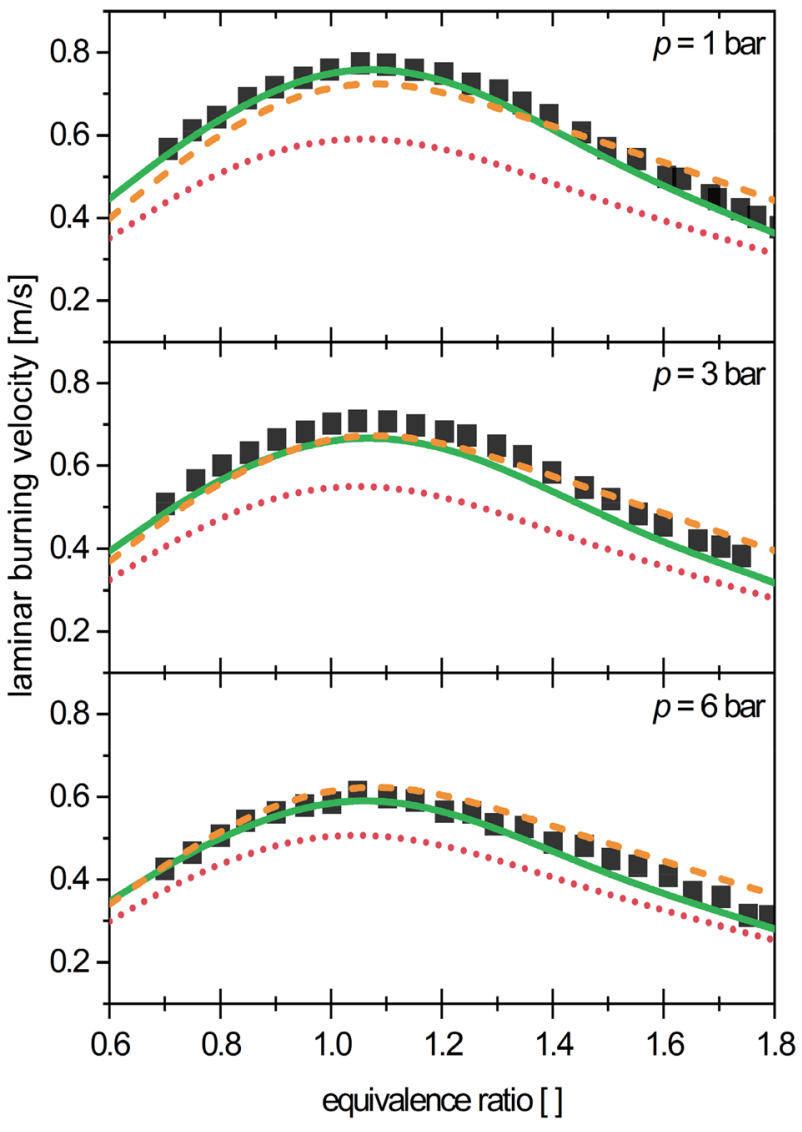

Fig. 9 Experimental laminar burning velocity results and model predictions for $\mathrm{C}_{2} \mathrm{H}_{6} / \mathrm{N}_{2} \mathrm{O}$ mixtures $\left(d\left(\mathrm{~N}_{2}\right)=50 \%, T=473 \mathrm{~K}\right)$ at $p=1$, 3, and 6 bar. Lines: simulations (red dotted: DLR SynNG+NO v0.0; orange dashed: DLR SynNG + NO v0.1; green solid: DLR SynNG + NO v0.2. Squares: experimental data from Richter et al. [20]

Acknowledgements The authors thank Juan Ramon Diaz Moralejo, Abhishek Verma, Alexander Vollmer, Bhaskar Bhatia, Myles Zabel, and Robert Djuric for their support carrying out the experiments. The support by DLR's Scientific Programme Administrations Energy, Aeronautics, Space and Transport in the frame of the QSP Future Fuels II Project is gratefully acknowledged.

Funding Open Access funding enabled and organized by Projekt DEAL. DLR internal Project "QSP Future Fuels II".

Availability of data and material All data and information being necessary to understand the study are given in the manuscript.

Open Access This article is licensed under a Creative Commons Attribution 4.0 International License, which permits use, sharing, adaptation, distribution and reproduction in any medium or format, as long as you give appropriate credit to the original author(s) and the source, provide a link to the Creative Commons licence, and indicate if changes were made. The images or other third party material in this article are included in the article's Creative Commons licence, unless indicated otherwise in a credit line to the material. If material is not included in the article's Creative Commons licence and your intended use is not

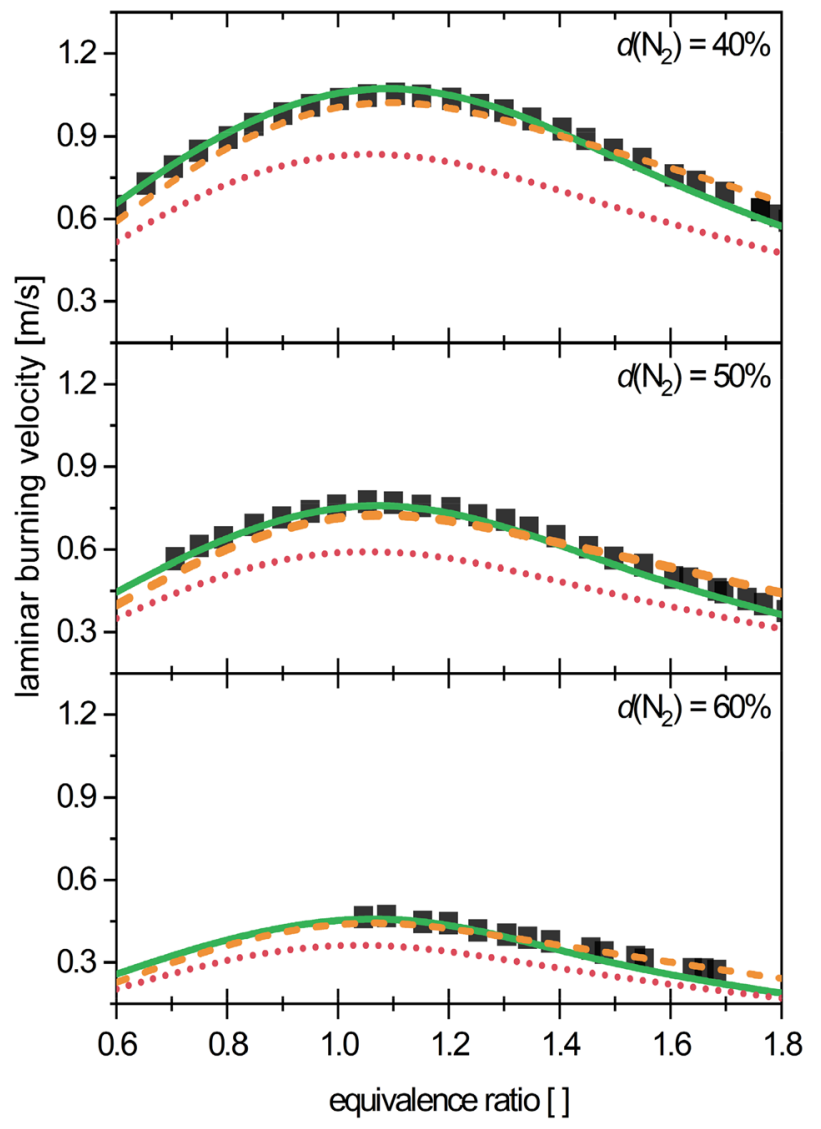

Fig. 10 Experimental laminar burning velocity results and model predictions for $\mathrm{C}_{2} \mathrm{H}_{6} / \mathrm{N}_{2} \mathrm{O}$ mixtures $(p=1$ bar, $T=473 \mathrm{~K}$ ) for different dilutions with $\mathrm{N}_{2}\left(d\left(\mathrm{~N}_{2}\right)=40,50,60 \%\right)$. Lines: simulations (red dotted: DLR SynNG + NO v0.0; orange dashed: DLR SynNG + NO v0.1; green solid: DLR SynNG+NO v0.2. Squares: experimental data from this work

permitted by statutory regulation or exceeds the permitted use, you will need to obtain permission directly from the copyright holder. To view a copy of this licence, visit http://creativecommons.org/licenses/by/4.0/.

\section{References}

1. Aggarwal, R., Patel, I., Sharma, P.B.: Green propellant: a study. Int. J. Latest Trends Eng. Technol 6(1), 83-87 (2015)

2. European Chemicals Agency (ECHA): General Report 2011The year of dissemination. (2012)

3. Ciezki, H., Zhukov, V., Werling, L., Kirchberger, C., Naumann, C., Friess, M., Riedel, U.: Advanced propellants for space propulsion-a task within the DLR interdisciplinary project" future fuels. In: Proc. 8th European Conference for Aeronautics and Space Sciences, (2019)

4. Werling, L.K., Hörger, T., Manassis, K., Grimmeisen, D., Wilhelm, M., Erdmann, C., Ciezki, H.K., Schlechtriem, S., Richter, S., Methling, T., Goos, E., Janzer, C., Naumann, C., Riedel, U.: Nitrous oxide fuels blends: research on premixed monopropellants at the german aerospace center (DLR) since 2014. In: Proc. AIAA Propulsion and Energy Forum, 3807 (2020) 
5. Werling, L., Lauck, F., Freudenmann, D., Weber, N., Ciezki, H., Schlechtriem, S.: Experimental investigation of the ignition, flame propagation and flashback behavior of a premixed green propellant consisting of $\mathrm{N} 2 \mathrm{O}$ and $\mathrm{C} 2 \mathrm{H} 4$. In: Proc. 7th European Conference for Aeronautics and Space Sciences, (2017)

6. Werling, L., Jooß, Y., Wenzel, M., Ciezki, H.K., Schlechtriem, S.: A premixed green propellant consisting of $\mathrm{N} 2 \mathrm{O}$ and $\mathrm{C} 2 \mathrm{H} 4$ : experimental analysis of quenching diameters to design flashback arresters. Int. J. Energ. Mater. Chem. Prop. 17(3), 241-262 (2018)

7. Keller, J.: DARPA works with five aerospace companies to develop inexpensive launch capability for small satellites. https:// www.intelligent-aerospace.com/military/article/16542246/darpaworks-with-five-aerospace-companies-to-develop-inexpensivelaunch-capability-for-small-satellites/ (2012). Accessed 13 August 2020

8. Gruss, M.: DARPA scraps plan to launch small sats from F-15 Fighter Jet. https://spacenews.com/darpa-airborne-launcher-effortfalters/ (2015). Accessed 13 August 2020

9. Tiliakos, N., Tyll, J., Herdy, R., Sharp, D., Moser, M., Smith, N.: Development and testing of a nitrous oxide/propane rocket engine. In: Proc. 37th Joint Propulsion Conference and Exhibit, 3258 (2001).

10. Mungas, G., Fisher, D.J., Mungas, C., Carryer, B.: Nitrous oxide fuel blend monopropellants. United States Patent US20090133788A1, (2009)

11. Mungas, G., Vozoff, M., Rishikof, B.: NOFBX: a new non-toxic, green propulsion technology with high performance and low cost. In: Proc. 63rd International Astronautical Congress, pp. 1-5 (2012).

12. Powell, O.A., Papas, P., Dreyer, C.: Laminar burning velocities for hydrogen-, methane-, acetylene-, and propane-nitrous oxide flames. Combust. Sci. Technol. 181(7), 917-936 (2009)

13. Powell, O.A., Papas, P., Dreyer, C.B.: Hydrogen- and C1-C3 hydrocarbon-nitrous oxide kinetics in freely propagating and burner-stabilized flames, shock tubes, and flow reactors. Combust. Sci. Technol. 182(3), 252-283 (2010)

14. Mathieu, O., Pemelton, J.M., Bourque, G., Petersen, E.L.: ShockInduced Ignition of Methane Sensitized by $\mathrm{NO}_{2}$ and $\mathrm{N}_{2} \mathrm{O}$. Combust. Flame 162(8), 3053-3070 (2015)

15. Wang, W., Zhang, H.: Laminar burning velocities of C2H4/N2O flames: experimental study and its chemical kinetics mechanism. Combust. Flame 202, 362-375 (2019)

16. Naumann, C., Kick, T., Methling, T., Braun-Unkhoff, M., Riedel, U.: Ethene/dinitrogen Oxide-a green propellant to substitute hydrazine: Investigation on its ignition delay time and laminar flame speed. In: Proc. 26th International Colloquium on the Dynamics of Explosions and Reactive Systems, vol. 30 (2017) https://elib.dlr.de

17. Kick, T., Starcke, J.H., Naumann, C.: Green propellant substituting hydrazine: investigation of ignition delay time and laminar flame speed of ethene/dinitrogen oxide mixtures. In: Proc. 8th European Combustion Meeting, (2017) https://elib.dlr.de

18. Naumann, C., Janzer, C., Riedel, U.: Ethane/nitrous oxide mixtures as a green propellant to substitute hydrazine: validation of reaction mechanism. In: Proc. 9th European Combustion Meeting, (2019) https://elib.dlr.de

19. Naumann, C., Kick, T., Methling, T., Braun-Unkhoff, M., Riedel, $\mathrm{U}$.: Ethene/nitrous oxide mixtures as green propellant to substitute hydrazine: reaction mechanism validation. Int. J. Energ. Mater. Chem. Prop. 19(1), 65-71 (2020)

20. Richter, S., Janzer, C., Methling, T., Naumann, C.: Green propellants for in-space propulsion: experimental and modelling study on the combustion chemistry of ethane/ethene-nitrous oxide mixtures. Space Propulsion 2020, SP2020_00524 (2021)

21. Methling, T., Braun-Unkhoff, M., Riedel, U.: An optimised chemical kinetic model for the combustion of fuel mixtures of syngas and natural gas. Fuel 262, 116611 (2020)

22. Glarborg, P., Miller, J.A., Ruscic, B., Klippenstein, S.J.: Modeling nitrogen chemistry in combustion. Prog. Energy Combust. Sci. 67, 31-68 (2018)

23. Goodwin, D.G., Moffat, H.K., Speth, R.L.: CANTERA: an objectoriented software toolkit for chemical kinetics, thermodynamics, and transport processes, version 2.2.1. https://cantera.org/. Accessed 07 August 2020

24. Methling, T., Braun-Unkhoff, M., Riedel, U.: A novel linear transformation model for the analysis and optimisation of chemical kinetics. Combust. Theor. Model. 21(3), 503-528 (2017)

25. Klippenstein, S.J., Harding, L.B., Glarborg, P., Miller, J.A.: The role of $\mathrm{NNH}$ in $\mathrm{NO}$ formation and control. Combust. Flame 158(4), 774-789 (2011)

26. Baulch, D.L., Bowman, C.T., Cobos, C.J., Cox, R.A., Just, T., Kerr, J.A., Pilling, M.J., Stocker, D., Troe, J., Tsang, W.: Evaluated kinetic data for combustion modeling: supplement II. J. Phys. Chem. Ref. Data 34(3), 757-1397 (2005)

27. Marshall, P., Ko, T., Fontijn, A.: High-temperature photochemistry kinetics studies of the reactions of hydrogen atom $(12 \mathrm{~S})$ and deuterium atom (12S) with nitrous oxide. J. Phys. Chem. 93(5), 1922-1927 (1989)

28. Hidaka, Y., Takuma, H., Suga, M.: Shock-tube study of the rate constant for excited hydroxyl $\left(\mathrm{OH}^{*}(2\right.$. SIGMA.+)) formation in the nitrous oxide-molecular hydrogen reaction. J. Phys. Chem. Ref. Data 89(23), 4903-4905 (1985)

29. Dean, A.M., Johnson, R.L., Steiner, D.C.: Shock-tube studies of formaldehyde oxidation. Combust. Flame 37, 41-62 (1980)

Publisher's Note Springer Nature remains neutral with regard to jurisdictional claims in published maps and institutional affiliations. 